\title{
REESTRUCTURACIÓN DEL VÍNCULO A TRAVÉS DE TERAPIA INTEGRATIVA EN UN CASO DE DUELOS MÚLTIPLES
}

\section{RESTRUCTURING THE BOND THROUGH INTEGRATIVE THERAPY IN A CASE OF MULTIPLE GRIEFS}

\author{
María Teresa Monjarás Rodríguez
}

Facultad de Psicología. Universidad Nacional Autónoma de México (UNAM). México ORCID. https://orcid.org/0000-0002-8196-3890

\section{Emilia Lucio y Gómez Maqueo}

Facultad de Psicología. Universidad Nacional Autónoma de México (UNAM). México ORCID. https://orcid.org/0000-0002-6098-940X

Cómo referenciar este artículo/How to reference this article:

Monjarás Rodríguez, M. T. y Lucio y Gómez Maqueo, E. (2020). Reestructuración del vínculo a través de terapia integrativa en un caso de duelos múltiples. Revista de Psicoterapia, 31(117), 347-366. https://doi.org/10.33898/rdp.v31i117.416

\section{Resumen}

Elobjetivo principal es describir el vínculo en la historia de M., un niño de 8 años, quién afronta diversas pérdidas y su relación con la presencia del duelo patológico; para ello fue necesario el análisis minucioso del caso de principio a fin del tratamiento, se audio grabaron las sesiones con el consentimiento del paciente y su tutor. Es importante mencionar que se realizó una evaluación diagnóstica completa con diversas pruebas psicológicas que abarcan las diferentes áreas (afectiva, percepto motora e intelectual).

A través del análisis de las sesiones se observa la dificultad de M para elaborar el duelo al no contar con una figura estable y segura que lo contuviera. Por medio del tratamiento terapéutico M logra establecer vínculos estables, afrontando asílas diferentes pérdidas.

Palabras clave: duelo, psicoterapia, integrativa,

\begin{abstract}
The main objective is to describe the bonding in the relationship of the story of M., an 8 year old boy, who faces several losses with the presence of pathological grief; for this purpose it was necessary the detailed analysis of the case from the beginning to the end of the treatment, the sessions were audio recorded with the patient and his guardian 's consent. It is important to mention that a complete diagnostic assessment was carried out with various psychological tests covering different areas (affective, intellectual, and visual perception).

Through the analysis of the sessions, it was observed that $M$ had difficulty with his grieving elaboration process because he did not have a stable and secure figure to contain him, the therapeutic treatment helped $M$ to establish stable bonds, thus facing the different losses.

Keywords: grief, psychotherapy, integrative, child, relational.
\end{abstract}


Tizón (2004) refiere que las primeras situaciones de pérdida de lo amado se dan ya desde los primeros momentos de la vida y de ahí también el papel crucial que juega la madre como el otro extremo primordial del ser humano en formación. Es la madre o sustituta, junto con el medio quien ayuda en la contención emocional de la pérdida, quien ha de ayudar a elaborar la compleja serie de sentimientos que su propia pérdida momentánea provoca: la sorpresa, el temor, las sensaciones desagradables, angustia, la ira, la rabia, el resentimiento, la desesperación, la desorganización que en ocasiones despierta en el bebé su marcha o desatención.

Si las pérdidas se acumulan y son negadas desde momentos muy tempranos del desarrollo del individuo, donde no hay una familia que contenga, por el contrario, se tiene una estructura familiar que dificulta la estructuración relacional y mental, entonces se favorece el desarrollo de trastornos mentales graves y relaciones familia-sociedad sumamente patológicas (Tizón, 2007).

En estos últimos años se ha acumulado abundante evidencia empírica que confirma la relación entre los estilos de vinculación del doliente y la posibilidad del desarrollo de duelo complicado. Los adultos con historias de vinculación insegura en su infancia van a presentar una mayor vulnerabilidad al desarrollo de duelos complicados cuando afronten situaciones de pérdidas. Y los vínculos ansioso-dependientes son un factor de riesgo que predice duelos crónicos, que no se concluyen con el tiempo (Bamba et al., 2017; Neymeyer y Woring, 2008; Payás, 2010; Tizón 2019).

A manera de síntesis podemos decir que la historia de apego del niño puede determinar las reacciones del duelo en la infancia y adultez temprana. Un apego inseguro o dañado incrementa el riesgo de un duelo complicado (Dyregrov, 2008). Sin embargo, también existen factores de protección mediadores que intervendrán más saludablemente en el proceso de superación de la adversidad y las pérdidas vitales, como son: la resiliencia, las fortalezas en las estructura de personalidad, el apego seguro, la adquisición de adecuadas estrategias de afrontamiento, un buen ajuste después de traumas o pérdidas anteriores, es importante detectar cualquier signo de riesgo en etapas tempranas de la vida familiar para con ello intentar paliar lo antes posible los efectos ocasionados por sucesos traumáticos y reducir las probabilidades del desarrollo de una posible psicopatología en el seno de las familias. Promover vínculos familiares saludables con una base segura, estilos de crianza democráticos y potenciar la capacidad resiliente de cada persona (Valero et al., 2016).

Para el trabajo psicoterapéutico realizado y descrito a continuación se retomó el modelo de psicoterapia integrativa de factores comunes, cuyo planteamiento fundamental hace referencia al hecho de que, si las psicoterapias curan de manera bastante similar, siendo tan diferentes como lo son teórica y metodológicamente, debe ser que curan por aquello que tienen en común y no por sus diferencias específicas (Frank et al., 1997; Rosado, 2007).

También se retoma la psicoterapia integrativa interpersonal, una psicoterapia 
que sustenta la relación entre el terapeuta y el cliente como elemento central de un proceso de cura y de crecimiento personal (Erskine, 2016).

Es importante considerar que en la actualidad se busca la evolución de la investigación de enfoques integrativos, tanto de la teoría como de sus aplicaciones, para que alcancen la madurez suficiente que permita reunir las pruebas de evidencia requeridas. Es posible pensar que existe un progreso en lo antes mencionado (Tena, 2020), sin embargo, existe limitada investigación considerando el análisis del vínculo y la manera de afrontar la pérdida en niños al inicio, durante y final del tratamiento desde el enfoque de psicoterapia integrativa, dicho análisis puede contribuir en el ámbito científico como a nivel de herramienta para la práctica terapéutica, así también para prevenir duelos complicados enfatizando la importancia del vínculo en la elaboración de la pérdida.

\section{Objetivo}

Describir el vínculo de M y su relación con la elaboración del duelo, al inicio, durante y final del proceso terapéutico utilizando la psicoterapia integrativa.

\section{Método}

\section{Tipo de estudio}

Cualitativo, donde la función del investigador cobra un nuevo valor, él es quien interpreta, da la comprensión, o la transformación, a partir de las percepciones, creencias y significados proporcionados por los protagonistas. Desde un punto de vista metafórico, se convierten en artistas recreando el mundo desde su mundo (Bisquerra, 2009).

La investigación cualitativa es la más adecuada para abordar un problema de investigación en el que no conoce las variables y necesita explorar. La literatura puede proporcionar poca información sobre el fenómeno de estudio, y es necesario aprender más de los participantes a través de la exploración (Creswell, 2015).

Específicamente se trabajará con el estudio de caso. Cozby (2005) menciona que el estudio de caso ofrece la descripción de un individuo, por su parte Creswell (2013) refiere que el estudio de caso es una exploración en profundidad de un sistema acotado (por ejemplo, el evento, proceso o individuo) que se basa en la recopilación extensa de datos.

\section{Instrumentos}

Para la evaluación diagnóstica se aplicaron diversos instrumentos:

Área emocional:

- Dibujo libre

- Dibujo de la figura humana (Koppitz, 2007)

- Test de la casa árbol persona (Buck, 1995)

- Test del dibujo de la familia (Corman, 1967) 
- Test del dibujo de la familia kinética (Burns y Kaufman, 1972)

- Test de apercepción temática para niños (Bellak, 1990)

Área perceptual:

- Dibujo de la figura humana (Koppitz, 2007)

- Prueba Gestáltica Visomotora de Bender (Bender, 1995)

- Evaluación de la Percepción Visual de Frostig DTVP-2 (Hammill et al., 1980)

Área intelectual:

- WISC IV (Wechsler, 2010)

\section{Procedimiento}

El presente caso se trabajó en un Centro de Servicios psicológicos, dentro del Programa de Residencia en Psicoterapia Infantil, Facultad de Psicología de la UNAM, 2012, el paciente es referido por paidopsiquiatra de un Centro de Salud Mental, para ser evaluado, así también para recibir tratamiento psicológico considerando presenta rasgos depresivos, el paciente presenta hidrocefalia congénita leve. Se obtuvo el consentimiento informado tanto del paciente como de su tutora para su publicación. La terapeuta a cargo fue María Teresa Monjarás Rodríguez, con supervisión de la Dra. Emilia Lucio Gómez Maqueo, quienes realizan la presente investigación.

La psicoterapia tuvo una duración de 1 año 4 meses (70 sesiones), distribuidas de la siguiente forma:

- Fase diagnóstica: en dicha fase se aplicaron pruebas proyectivas, psicométricas, dibujo libre y juego diagnóstico (Sesión 1 a la 13).

- Fase inicial: tratamiento inicial a través del juego libre, establecimiento del encuadre. Fortalecimiento de alianza terapéutica (Sesión 14 a la 31).

- Fase intermedia: se manejaron los principales conflictos de acuerdo con las necesidades del paciente, relacionadas con los focos de intervención (Sesión 32 a la 47).

- Fase final: se observan avances, tanto M como la familia habla de los avances. Se realiza el cierre del tratamiento con consideraciones de seguimiento (llamada telefónica cada semana durante dos meses)(Sesión 48 a la 70$)$.

Es importante señalar que también se tuvieron alrededor de 25 sesiones con la madre.

En principio se muestran los antecedentes del caso y la evaluación realizada en la fase diagnóstica para una mayor comprensión.

Se transcribieron cada una de las sesiones y se realizó el análisis de la fase inicial, intermedia y final, considerando los siguientes criterios:

- Vínculo con figuras parentales: (seguro, inseguro, desorganizado).

- Dificultades del duelo: ansiedad persistente relacionada con el temor de sufrir otra pérdida, temor de morir él también, esperanzas de reunión y 
deseos de morir, persistencia en culpar o culparse.

- Elaboración del duelo: proceso de confrontación y exploración, proceso de negociar y renegociar nuevos sentidos.

El análisis fue realizado por la terapeuta Teresa Monjarás, finalmente la Dra. Emilia Lucio hizo una revisión del análisis.

En el presente trabajó se presentan los temas principales abordados en cada una de las fases con relación al vínculo y duelo, segmentos de las sesiones más representativas de cada fase y un breve análisis considerando los criterios antes mencionados.

\section{Caso clínico}

A continuación, se presentan los datos generales (tabla 1), genograma del caso (figura 1) y motivo de consulta.

Tabla 1. Datos Generales

\begin{tabular}{llll}
\hline Nombre: & M. Y. (Paciente) & E. (Madre de M) & D. (Padre de M) \\
\hline Edad: & 9 años & 34 años & $\begin{array}{l}\text { Se suicida a los 29 } \\
\text { años }\end{array}$ \\
\hline Escolaridad: & $3^{\circ}$ primaria & $\begin{array}{l}\text { Pasante en } \\
\text { Sociología }\end{array}$ & $\begin{array}{l}\text { Pasante en } \\
\text { Economía }\end{array}$ \\
\hline $\begin{array}{l}\text { Fecha de } \\
\text { nacimiento: }\end{array}$ & 2002 & 1977 & $\begin{array}{l}1972-2003 \\
\text { Finado }\end{array}$ \\
\hline Ocupación: & Estudiante & $\begin{array}{l}\text { Ayuda a la madre } \\
\text { en comercio }\end{array}$ & - \\
\hline Estado civil: & Soltero & Soltero & Soltero \\
\hline
\end{tabular}




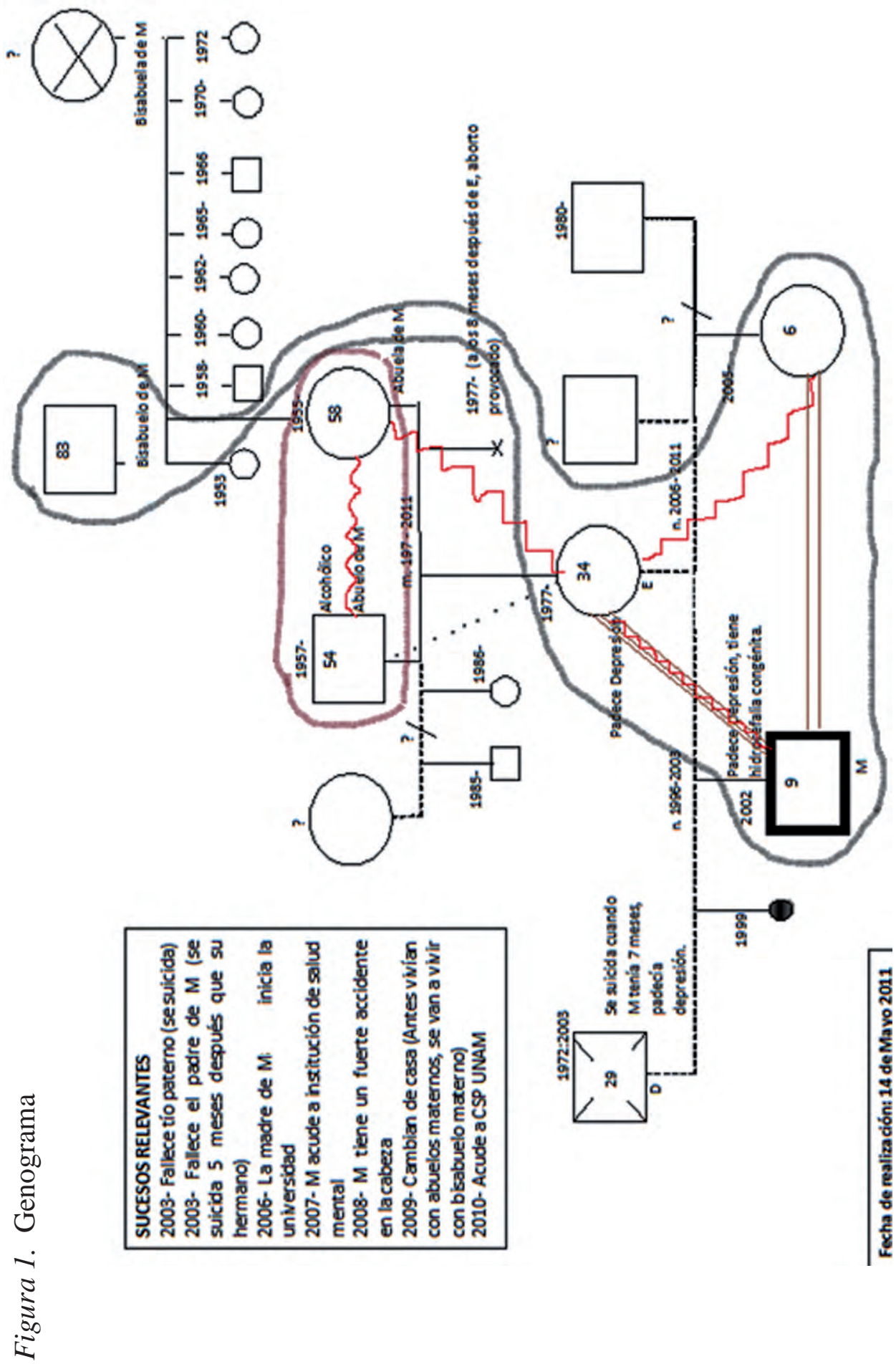




\section{Motivo de consulta}

A M. lo refiere el paidopsiquiatra de un Centro de Salud Mental para realizar valoración psicológica e intelectual con la finalidad de descartar retraso mental, también es referido para que sea atendido el aspecto emocional, pues fue diagnosticado con depresión. Desde los 4 años acude a este centro pues hablaba de la muerte y decía que desearía ir con su papá.

\section{Historia del problema}

La familia de $M$ está integrada por su madre y media hermana de 6 años. El padre de $M$ no se responsabilizó de éste pues a partir de que se entera del embarazo se separa de la madre. El padre muere a los 7 meses de nacimiento de $\mathrm{M}$ por suicidio (se ahorca). Actualmente $\mathrm{M}$ tiene poco contacto con la abuela paterna, la llega a ver dos veces al año. La madre de M refiere padecer depresión.

El principal sostén económico en la familia de M es la madre, aunque la mayoría de las veces la abuela materna le ayuda en los gastos.

Según lo reportado por la madre se observa que hay violencia psicológica de parte de ella hacia sus hijos y poca comunicación. La madre se siente muy preocupada y tiende a culpabilizarse pues se da cuenta que usa la violencia verbal y en ocasiones física.

La relación entre M y su hermana tampoco es estrecha, tienden a competir por el cariño de la madre. Por momentos $\mathrm{M}$ se muestra muy cariñoso y amable con su hermana, pero en ocasiones la agrede y tiende a jugar toscamente con ella.

Actualmente $\mathrm{M}$, su madre y hermana viven en la casa de su bisabuelo paterno, dentro de un terreno familiar donde también viven sus tíos y primos.

Durante el día M y su hermana van a la escuela y por la tarde están solos o a veces sus abuelos paternos van a la casa del bisabuelo para preparar los tamales que venderán al día siguiente, al respecto la abuela comenta "Yo solo voy a preparar los tamales y a veces les doy de comer, pero no me encargo de cuidarlos".

$\mathrm{M}$ en alguna de las sesiones comenta que su abuela y madre pelean mucho, él trata de no inmiscuirse en las peleas; dice tener buena relación con su abuela.

La abuela refiere que cuando su hija era pequeña la golpeó mucho ya que su esposo era alcohólico e infiel, en ocasiones ella descargaba su coraje en su hija, menciona que ha tratado de tener una buena relación con su hija, pero se le dificulta demasiado.

\section{Antecedentes clínicos personales}

M. sufre de Hidrocefalia congénita diagnosticada a los 6 años, esto le provoca dificultades motrices. La madre y abuela no se explican por qué la hidrocefalia no fue diagnosticada desde el nacimiento o por el pediatra, ya que lo llevaban cada mes a revisiones.

Desde los 4 años es diagnosticado por paidopsiquiatra con depresión debido a rasgos genéticos. Le realizan un encefalograma y le dicen que M presenta 
inmadurez y trastornos emocionales. Acude cada 6 meses con el paidopsiquiatra, no toma medicamentos para tratar los trastornos emocionales, aunque sí han sido recetados por el paidopsiquiatra, la madre se resiste a dárselos al considerar que pueden dañar su estómago. Es importante señalar que, a partir de la fase intermedia del tratamiento con $\mathrm{M}$, la madre muestra aceptación y mayor constancia para dar el medicamento a su hijo.

A continuación, se presentan los resultados de las pruebas realizadas en la fase diagnóstica por la psicoterapeuta infantil Teresa Monjarás.

\section{Resultados de las pruebas}

\section{Área intelectual}

M muestra una capacidad normal que le permite responder adecuadamente al ambiente, presenta un CIT $=97$, el cual se puede interpretar debido a que la diferencia entre la puntuación estándar de los índices no rebasa los 23 puntos (Flanagan y Kaufman, 2009). En cuanto al análisis de los índices se observa que el índice de razonamiento perceptual y velocidad de procesamiento no son interpretables debido a que la diferencia entre las puntuaciones escalares es igual o mayor a 5.

En la Figura 2 se puede observar que muestra algunas dificultades especialmente en tareas que requieren de habilidad motriz y precisión en el análisis visual. M deja ver sus dificultades para responder tareas que requieren tiempo bajo presión, mostrando su baja tolerancia a la frustración. Otra de sus dificultades se observa en tareas que requieren de la percepción de detalles, en ocasiones le cuesta trabajo concentrarse sin embargo puede ser capaz de hacerlo si no se siente presionado y le interesa la actividad, como por ejemplo en problemas matemáticos, donde su desempeño es favorable.

Dentro de sus fortalezas se observa un buen nivel en el razonamiento abstracto categórico con el manejo de imágenes, razonamiento verbal, formación de conceptos, capacidad de aprendizaje y memoria, ésta última le ayuda a recordar palabras poco comunes que lee o escucha. 
Figura 2. Resultados del WISC IV
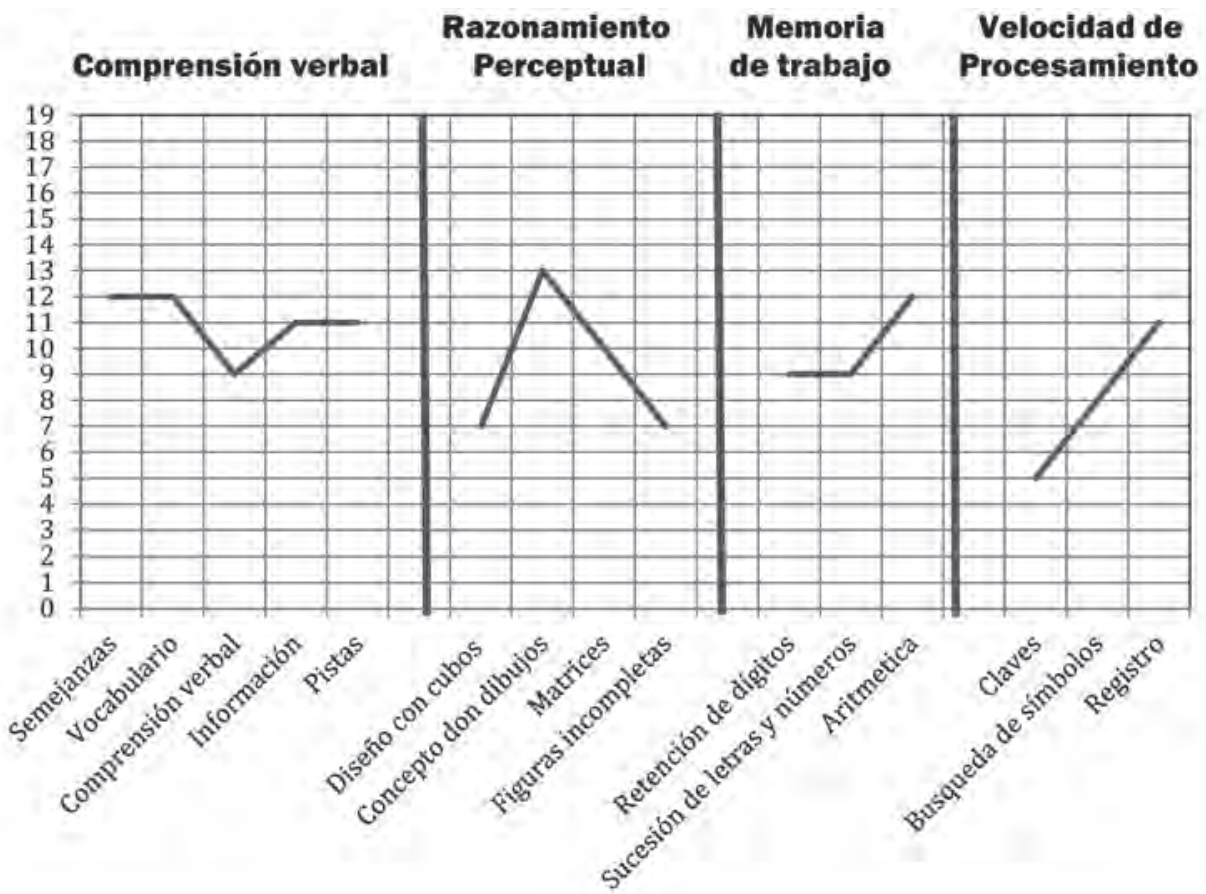

INDICE DE COMPRENSION VERBAL: 104

\section{C.I. TOTAL: 97}

INDICE DE MEMORIA DE TRABAJO: 94

INDICE DE RAZONAMIENTO PERCEPTUAL: 100

INDICE DE VELOCIDAD DE PROCESAMIENTO: $\underline{88}$

\section{Área percepto motora}

En la figura 3 se observan dificultades con relación a tareas de percepción visual general, tanto en tareas visuales como motoras. La principal dificultad que presentó $\mathrm{M}$ se observa en tareas que requieren de poner atención al detalle. La habilidad motriz en coordinación con estímulos visuales es deficiente la cual se manifiesta en la dificultad para dibujar y mantener la escritura en el renglón, escribe muy lentamente o muy aprisa sin controlar todos sus movimientos, lo cual se refleja en su mala letra y baja calidad en el dibujo.

En cuanto a la percepción en el espacio muestra dificultades para tener un dominio estable de la mano, presenta problemas con la lateralidad, percibir objetos que están detrás, por delante, por abajo o al lado de sí mismo. 
Figura 3. Resultados Frostig DTVP-2

\section{Frostig DTVP-2}

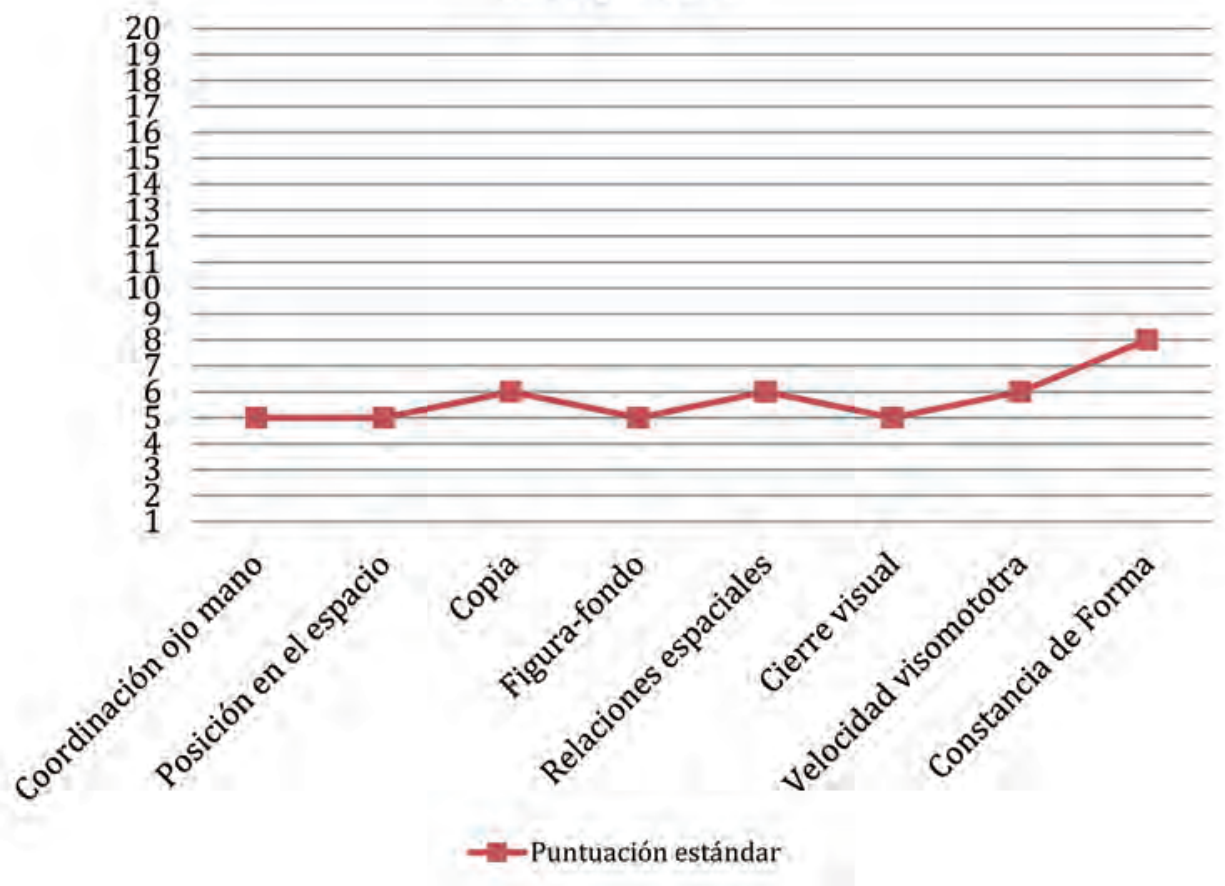

\section{Área afectiva}

Se observa que M tiene un pobre auto concepto al percibirse como una persona indefensa, inferior, con poca capacidad para solucionar sus conflictos, en ocasiones muestra desesperanza aprendida, se percibe como inseguro, inadecuado al entorno, agresivo y con necesidad de reconocimiento y apoyo, se muestra dependiente, especialmente a la figura materna. Se observa poca diferenciación con la madre y hermana. Se identifica con la agresión y falta de comprensión de la figura masculina.

Presenta sentimientos ambivalentes hacia su hermana, la percibe como cercana, pero al mismo tiempo se observa rivalidad entre ellos. M deja ver un temor significativo a perder los objetos de amor (madre, abuela, hermana, etc.), lo cual puede estar asociado a su vínculo inseguro, principalmente con la madre. Cabe señalar que cuando la madre se enoja con M, le dice "tu papá murió de depresión, él no te quería”, lo cual provoca en M sentimientos de tristeza. En las pruebas proyectivas M refleja sentimientos de culpa al tener la fantasía de que él fue responsable por la muerte del padre.

Las palabras que la madre le ha dicho a M parecen tener una repercusión importante en él al considerar que las palabras dan forma a nuestras ideas y significado a nuestras experiencias (Freeman et al., 2001), las palabras cómo “eres un estúpido, tonto estoy harta de ti, tu papá no te deseaba”, se relacionan con los sentimientos 
de inferioridad, incapacidad y auto concepto devaluado de M.

\section{Impresión diagnóstica}

M presenta rasgos de un trastorno depresivo persistente: estado de ánimo deprimido durante la mayor parte del día, falta de concentración, falta de desesperanza, baja autoestima, dificultad para tomar decisiones, sentimientos de desesperanza por más de dos años (Asociación Americana de Psiquiatría, 2014). También se observan duelos no elaborados (pérdida del padre, pérdida del vínculo materno, pérdida física por hidrocefalia congénita) principalmente la pérdida del padre. Al respecto Bowlby (1993), señala que algunos de los síntomas de los niños que han sufrido una pérdida son: ansiedad persistente relacionada con el temor de sufrir otra pérdida, temor de morir él también, esperanzas de reunión y deseos de morir, persistencia en culpar o culparse, hiperactividad; también habla de los síntomas identificatorios donde la persona que sufrió la pérdida manifiesta síntomas que son réplicas de los síntomas que tuvo la persona muerta.

\section{Focos de intervención}

- Favorecer su auto concepto y autoestima

- Descubrir al "Yo", en toda su dimensión, no sólo limitaciones (hidrocefalia)

- Resignificar vínculos

- Elaboración del duelo por la muerte del padre. (Concepto de muerte)

- Diferenciación entre él y madre. Identificación proyectiva-padre

- Ayudar a integrar objetos

- Control de impulsos

- Rivalidad fraterna

\section{Intervenciones terapéuticas}

- Acompañamiento en el juego

- Señalamientos y reflejos en el juego

- Reconocimiento de habilidades (reforzamiento)

- Focusing

- Establecer principio de realidad

- Interpretaciones en el contenido del juego

Es importante señalar que $\mathrm{M}$ acudía al área de neuropsicología para el tratamiento en el déficit de algunas habilidades cognitivas y motoras.

\section{Análisis del caso}

A) Fase inicial (Sesión 14 a 31)

\section{Vínculo con sus cuidadores principales}

Temas principales. Inseguridad en el vínculo afectivo principalmente con sus abuelos maternos y madre, expresa su miedo a que lo abandonen su madre y abuela, así como su enojo hacia dichas figuras, refiere su ideal de tener una familia 
armoniosa. Se observan descalificaciones y ofensas constantes entre los personajes del juego.

Ejemplo:

M: Paciente M.

T: Terapeuta

"Sesión 17"

M toma los juegues, play mobile y dinosaurios para jugar y realizar una historia, al final el personaje de play mobile dice:

M: "la violencia es la forma más eficaz de matar, mis padres me enseñaron a ser violento, a mis padres no les importaba que fuera bueno, le hacía de comer a mamá, le traía periódico a papá, y siempre me decían que debía ser violento, hasta que un día mi papá me pegó tan fuerte que olvidó todo su bondad y se volvió violento, pero ahora si ya desperté, ahora si ya vamos amigos, no tan rápido, que aaaaaaaaaaa”".

Al terminar la sesión $\mathrm{M}$ expresa su enojo hacia la gente que lo ha maltratado, como sus primos, quienes se burlan de él y su madre que lo ofende verbalmente y agrede físicamente.

T: "Pero algo que si es cierto es que tú tienes muchas habilidades cómo en las matemáticas. Sacaste buenas calificaciones, me dijo tú mamá, felicidades, aunque la maestra no se porto muy bien y te bajo un punto"

M: "Saque 8.6”

T: "Muchas felicidades"

M: "Mi mejor materia fue cívica y ética saque 10"

T: "Muchas felicidades"

$M$ : "No sé ni cómo saque 10"

T: "Eres muy inteligente, la próxima sesión podremos hablar más de esto"

Análisis. M deja ver el vínculo inseguro desorganizado con sus figuras parentales, así como su impotencia al "no ser visto”, parece que en ocasiones se empeña por tener un buen comportamiento, pero el resultado es el mismo “agresiones”. M muestra su enojo ante las agresiones que recibe de su familia, así también deja ver su necesidad de ser reconocido y mirado por otros, al respecto Dolto (1983) menciona que el ser humano interioriza el código de su relación con el otro, se ama así mismo como es amado por otro. Durante la fase inicial se observó que ante la separación muestra enojo, reflejando un tipo de apego inseguro desorganizado pues en algunas sesiones no mantiene contacto visual, por momentos si lo hace, pero muestra cierto enojo, ignorando lo que dice la terapeuta, en ocasiones tartamudea y muestra un lenguaje desorganizado. Se observa temor a perder a las figuras significativas para él.

\section{Duelo}

Temas principales. A través del juego representa sus fantasías con relación a cómo murió su padre (los personajes del juego mueren ahorcados, asesinados o 
saltan de algún edificio), representa el anhelo por la persona pérdida y persistencia a culpar o culparse. Expresa su tristeza por diferentes pérdidas, en el juego los personajes expresar su temor a morir en muertes trágicas, expresa su miedo, así como su enojo con relación a la hidrocefalia.

Ejemplo

"Sesión 16"

M: "Estoy muy deprimido porque mi abuela me contó que el hermano de mi papá murió asesinado, después mi papá se deprimió y por eso murió” T: "¿Qué sientes en este momento?"

M: "Me da tristeza no haber podido hacer algo"

T: "Tú eras un bebé y no podías hacer nada"

"Sesión 29"

M: "Casi siempre he perdido a mis perros, mi perro Jairo murió de una forma muy fea, se cayó del barranco, estaba en el terreno de mi abuelo, vi que mi perro se cayó del barranco y me sentí muy triste"

T: "Yo también me hubiera sentido triste"

M: "Sí, es muy triste cuando pierdes a los que quieres, animales o personas, yo a veces pienso que mi papi puede regresar, quisiera que regresara, es que yo lo necesito, yo le digo papá a mi abuelo y él es muy bueno, pero yo necesito a mi papá”.

Análisis. En esta fase M habla directamente de sus diferentes pérdidas: por ejemplo, la pérdida física por hidrocefalia, pérdida de sus seres queridos, tales como mascotas y principalmente la pérdida de su padre, expresa sus deseos de reencontrarse con su padre. Posiblemente fantasee que su padre murió de la misma forma que su perro Jairo, parece que, ante la incertidumbre de los acontecimientos sobre la muerte de su padre, M llega a tener muchas fantasías (por ejemplo, que murió asesinado, ahorcado, se aventó de un edificio). Bowlby (1993), señala que algunos de los síntomas de los niños que han sufrido una pérdida son: ansiedad persistente relacionada con el temor de sufrir otra pérdida, temor de morir él también, esperanzas de reunión, mismos que se muestran en la primera fase de tratamiento.

B) Fase intermedia

\section{Vínculo con sus cuidadores principales}

Regreso de vacaciones

Temas principales. Reconocimiento de sí mismo, expresa necesidad de establecer un vínculo seguro, necesidad de una figura parental que no lo abandone y brinde seguridad, va percibiendo en el abuelo una figura que no lo abandona, comienza a verbalizar a través del juego que hay personas que lo escuchan, que no lo engañan ni lo maltratan.

Ejemplos:

"Sesión 38":

M tomó a los niños play mobile y juega con ellos

M: "Mira como los niños hacen diferentes trucos en la moto" 
T: “¿Quién les enseño?”

M: "Los padres les enseñaron, mira pasan por diferentes obstáculos” "Lo van a lograr, entre ellos se dan consejos para hacerlo cada vez mejor, no tienen miedo"

Al final de la sesión:

M: "Voy a nombrar a los personajes el niño de color rojo se llama Rudy, naranja Beny y el verde Myke” “¿Cómo quieres que se llamen las niñas?” T: "Una podría ser Lulu"

M: "Sí, otra podría ser Stefany y otra Fabiola, la mujer grande guerrera se llama Natalia"

Análisis. M comienza a percibir el espacio como seguro, genera un vínculo seguro con el espacio y terapeuta, se da cuenta de que ante la separación no será abandonado ni dejará de ser querido, cabe señalar que, en la fase inicial ante un periodo de vacaciones, regresaba molesto y tendía a ignorar a la terapeuta. En esta sesión nombra a los personajes, lo cual tiene un importante significado simbólico pues como menciona Lebovici y Halpern (2006), el nombre del bebé le prepara el futuro; es importante recordar que anteriormente $\mathrm{M}$ nombra al personaje con el que se identifica Dany, al igual que su padre, identificándose con ese ser muerto y ausente, en ésta sesión al personaje que sobresale y con quien se identifica lo nombra "Mike", comienza con la letra de su nombre $\mathrm{M}$, lo anterior deja ver que $\mathrm{M}$ se va reconociendo. Comienza a percibir un vínculo seguro con su abuelo.

\section{Duelo}

Temas principales. Expresión y manejo del enojo ante la pérdida, refiere sus impulsos agresivos y temor ante estos, deseos de venganza contra quienes ha relacionado con sus pérdidas (por ejemplo, la persona que atropello a uno de sus perros, contra quién piensa mato a su tío). Refiere deseos de ver a su padre muerto, culpa a los otros de sus pérdidas. Expresa temor ante la pérdida. Inicia elaboración de la pérdida paterna.

Ejemplos:

"Sesión 33 y 34":

M: "Me ha llegado un dolor de cabeza"

T: "A veces eso pasa cuando algo nos causa angustia"

M: "Es que a veces también me pasa eso, es que extraño a mi padre, es que me hicieron hacer dibujos con mi otra terapeuta, dibujo de mi familia y no dibuje a mi papá porque estaba muerto, es que varios de mis primos comparten esto, Rodrigo, se murió su papá” “yo le pedí a una estrella que reviviera mi papá”

T: "Eso no es posible, pues la gente que muere ya no regresa"

M: "yo deseo que regrese"

T: “¿Para qué?"

M: "Para verme, para verlo solo una vez, acaso es mucho pedir verlo solo 
una vez".

T: "Entiendo es algo que te duele y eres muy valiente de expresarlo. ¿Dónde te duele cuando piensas en eso?”

M: “En mi corazón, quiero que mi papá esté, por favor, Dios”

T: “¿Cómo es ese dolor?”

M: "Es muy muy grande, mucha tristeza, es de color negro, siento rabia porque si no hubiesen matado al hermano de mi papá, él no se hubiera entristecido y no hubiera muerto, siento rabia con la persona que mató a mi tío, ¿por qué no fueron asaltar a otra persona? ¿por qué, por qué? ¿por qué nadie lo defendió?, él estaría vivo”.

T: “¿Cómo es ese enojo?”

M: "Es duro duro y se mueve muy rápido rápido, ahorita mi cerebro anda pensando que él estaría conmigo”

T: “¿Qué le dirías a las personas que mataron a tu tío?”

M: "Les diría que no los perdonaría, no tendría piedad de ellos, pues por ellos ni siquiera lo conocí"

T: "Es como si te lo hubieran arrebatado"

M: "Sí”"

T: “¿Qué te gustaría decirle a tu papá si estuviera vivo?

M: "Que lo extraño y quiero mucho"

T: “QQué crees te diría tu papá a ti?”

M: "Que me quiere”

T: “¿De qué cosas crees que estaría orgulloso?

M: "De que no me he rendido en tercer año, de que he logrado sobrevivir a la hidrocefalia, de que a pesar de que me caí aún sigo vivo”

T: "Tú has luchado por estar aquí"

"Sesión 42"

Durante el juego toma al personaje Mike y sus hermanos, la terapeuta toma el personaje de la hermana

M: "Mike extraña a su padre y su hermano le dice que no puede vivir toda la vida así"

T: "Puedes recordar las cosas buenas de él"

M: “Mi padre era valiente como nosotros, murió defendiéndonos y no le gustaría ver a sus hijos en una guerra, pero sus hijos lo hacen pensando que de esa forma su padre se enorgullecería de ellos, si estuviera vivo”. "Su hermano le dice a la hermana que murió por su culpa pues ella se salió de la cuna y los malos la siguieron hasta donde estaba su papá, la niña dice que ella era solo un bebé y comienza a llorar, otra de las niñas le dice que no fue su culpa. Mike le dice a su hermano que no fue culpa de ella, que su padre ha muerto y no fue culpa de nadie, el hermano dice que pudieron haberlo salvado, Mike menciona que eran solo unos niños, su hermano dice que tiene razón y le pide disculpas a su hermana, diciéndole que estaba 
enojado y por eso lo dijo"

Análisis. Durante esta fase se observa el anhelo de M porque su padre se encuentre con él, persiste en él la incredulidad de que la pérdida sea permanente. M muestra enojo y reproche a las personas que mataron a su tío, cabe señalar que su abuela le dice que a su tío lo asaltaron y lo mataron, entonces su padre entristeció, le dio depresión y murió; la realidad es que su tío también se suicidó con anticongelante. En esta sesión se aplica el Focusing (Stapert y Verliefde, 2011) con la finalidad de que $\mathrm{M}$ reconozca y hable de las emociones que siente con respecto a la muerte de su padre puesto que en casa esto no lo puede hacer, debido a que su madre muestra enojo o llanto. Aunque M no conoció a su padre, dice extrañar a dicha figura, posiblemente ante su dificultad por encontrar una figura que cumpla con las funciones paternas, así como por las verbalizaciones de su madre con respecto a la muerte de su padre "tu padre murió después de que naciste, él no quería que nacieras".

M desea reafirmarse, pensando que sus padres están orgullosos de él, comienza a disminuir su culpa ante las pérdidas. Fue necesario su auto afirmación y reconocimiento para poder confiar en que no perderá a todos sus seres queridos por tener o ser algo malo como parecía percibirlo, sino que en ocasiones todos llegamos a tener pérdidas que no tienen que ver con lo que somos.

C) Fase intervención final

Vínculo con sus cuidadores principales

Temas principales. Manejo de la ansiedad ante la separación, vínculo seguro con hermana, cierre terapéutico.

Ejemplo:

"Sesión 57"

Regresando de vacaciones, dentro del juego:

M: “¿Dónde está el guerrero?, el guerrero nos abandonó, no nos abandonó se lo llevaron a Tahití", "A Tahití, tan lejos sólo para eso" "Para combatir, tú no lo harías para salvar a esa área”.

"Sesión 65"

M: "Hoy no me fue bien en la escuela, estaba jugando con mi hermana con una pelota y nos peleamos por ella, ya después me la presto, pero se me perdió la pelota y lloraba en mi interior porque no puedo llorar ya que los otros se burlan, mi hermana me vio triste y me dijo que no me preocupará pues sólo era una pelota”

T: "Tú hermana te comprendió"

M: Sí

En el juego:

M: "El personaje de Mike le encarga su perrito a su hermana para que no lo ataquen, la hermana lo cuida".

Análisis. En esta fase disminuye la ansiedad de separación, se observa que $\mathrm{M}$ establece una relación menos conflictiva con su hermana, la percibe como una 
red de apoyo, una figura que lo puede llegar a comprender, vínculo seguro. Parece ser que $\mathrm{M}$ comienza a transferir la seguridad que encontró en el espacio y en la relación con la terapeuta, a otros espacios, como en el familiar, específicamente con su hermana y abuelo. Percibe que no está solo y puede enfrentarse a las diversas adversidades, con el apoyo de los otros.

\section{Criterios de duelo patológico}

Temas principales. Abuelo como figura paterna, resignificación de la pérdida, nuevos vínculos.

Ejemplo:

"Sesión 57"

En el juego:

M: "Pelean los buenos y los malos, pero no sé si tomar a los niños o a los adultos, ¿vamos al pasado o al futuro?, vamos al pasado"

M: "Ganaron los niños buenos, en serio nunca los olvidaré niños, son muy importantes y espero haya oportunidad de regresar a ser niños de nuevo, extrañaré sus caras, están listos para irse, listos, listos” “Adiós, adiós” "Sesión 68 "

T: "Está por finalizar la terapia, ¿Cómo te sientes de la fiesta de graduación que haremos?

M: "Alegre"

T: “¿De qué te sientes alegre?”

M: "De que ya no chillo tanto como antes por mi papá”. "La próxima vez en el juego se mostrará cómo le ha hecho Tarzán para mantenerse tan fuerte" T: "Tú también eres una persona fuerte"

M: "Papá José es muy bueno y me quiere mucho, aunque a veces me hace comer cosas que no me gustan como el pescado, chayote y la calabaza, pero lo hace por mi bien". "Mi papá D se murió, él no estaba listo para ser papá, pero también lo quiero mucho"

T: "¿Quién te dijo que no estaba listo para ser papá?

M: "Mi mamá, él me quería abortar porque no se sentía preparado para ser papá, pero él si me quería porque dice mi mamá que cuando estaba vivo le contó que me soñó una vez tocando una canción”

T: "Tú papá sí te quería y si tu madre te hubiese abortado tu padre se hubiese puesto muy triste al igual que tu mamá”

M: "Papá murió de depresión porque se murió su hermano menor y él se sintió muy triste y ese dolor lo mató, se deprimió mucho".

T: "Tu madre me comento que le preguntaste si tu padre se suicidó" "¿sabes que es suicidio?"

M: "si, cuando tú te matas"

T: “¿Tu papá se suicidó?”

M: “no, mi papá entro al cielo”

T: "Cuando una persona se suicida no entra al infierno" 
M: “¿Existe el infierno?

T: "En realidad nadie lo sabe, pero desde la religión que ustedes practican se sabe que Dios conoce los corazones de quienes se suicidan, sabe las cosas buenas que hicieron y les permite entrar al cielo, la gente que se suicida no es mala, sino que en ese momento se dejaron llevar por la tristeza y no encontraron la forma de sentirse mejor".

Última sesión:

M: "Hemos perdido muchos amigos en estas batallas, nuestros padres murieron, pero también hemos encontrado nuevos amigos y una nueva familia".

Análisis. Se presenta la resignificación de la pérdida y la oportunidad que se da para establecer otros vínculos. Reconoce sus logros y dice estar preparado para nuevas batallas. Presenta tristeza ante las pérdidas, sin embargo, al final refleja cierta aceptación, percibiendo que continuará recordando y valora lo positivo, cabe mencionar que anteriormente se enfocaba en lo negativo de su relación con lo perdido u otros aspectos negativos, como la forma catastrófica de las pérdidas.

\section{Discusión}

Con el presente trabajo se confirma la relación entre el tipo de apego inseguro y la posibilidad del desarrollo de un duelo complicado, sumado a una percepción baja de redes de apoyo dentro de la familia (Neymeyer, 2019), como lo es en el caso presentado donde $\mathrm{M}$ presenta una historia de apego inseguro ansioso y ambivalente a lo largo de su vida, lo cual repercute en su forma de afrontar las pérdidas, muestra ansiedad significativa, culpa, autorreproche y tiende a deprimirse, esto relacionado con las experiencias de abandono vividas durante su infancia por sus cuidadores principales, cada vivencia de pérdida la vive como un abandono de la persona amada, lo que le lleva a pensar que no es lo suficientemente valioso. Lo anterior se puede observar especialmente en la primera fase del tratamiento.

En la segunda fase del tratamiento $\mathrm{M}$ expresa su enojo, tristeza, deseos de venganza en cuanto a la pérdida, al respecto Erskine (2016) refiere que, en la psicoterapia del duelo, desde la psicoterapia integrativa relacional, cuando el duelo es prolongado puede ser importante comenzar con la rabia, amargura, así como facilitar la consciencia del cliente sobre su tristeza por los sueños truncados y recodar, lo anterior se logró aplicando la técnica de Focusing.

En la tercera fase $\mathrm{M}$ establece un vínculo seguro con abuelo y hermana y terapeuta, al respecto Erskine (2016) refiere que un psicoterapeuta afectivo y rítmicamente sintonizado, proporciona, al paciente, esa otra persona significativa que es sensible, respetuosa, validadora consistente y fiable. El apoyo y vínculo seguro con las figuras antes mencionadas, así como la resignificación del evento favorecen la elaboración del duelo. Neimeyer y Woring (2008) mencionan que contar la propia verdad, la narrativa personal, es un factor esencial para otorgar sentido, completando las experiencias inconclusas significativas y proporcionando un final al duelo prolongado. 
Es importante destacar la búsqueda de factores protectores contra el duelo patológico (Tena, 2016) tales como: apoyo familiar, apoyo social el apego seguro, la adquisición de adecuadas estrategias de afrontamiento, los cuáles se lograron observar al final del tratamiento.

Concluimos sobre la importancia del trabajo de psicoterapia integrativa relacional en el duelo donde es importante reconocer los sentimientos negados, emplear métodos expresivos (activos) en la cura del dolor emocional y del enfado, proporcionar tiempo y el espacio suficiente para que la persona relate su historia y para que concluya el "asunto pendiente”, brindar una relación de apoyo mediante la implicación del psicoterapeuta, ayudar al cliente a que pueda fluir entre sus diversas respuestas emocionales tales como negación desesperación, anhelo, rabia, ayudarle también en la reorganización del self (Erskine, 2016); lo anterior sumado a la búsqueda y promoción de factores protectores contra el duelo patológico.

También es importante destacar la relevancia de la psicoterapia de juego (Esquivel, 2010) en el trabajo con niños, incluso desde la psicoterapia integrativa relacional, pues la aplicación de ésta última no puede ser la misma en niños que en adultos, considerando que su desarrollo cognitivo, social y emocional es distinto. El presente trabajo contribuye a la aplicación de la psicoterapia integrativa relacional, específicamente en el trabajo con niños en duelo.

\section{Agencia de Apoyo}

Universidad Nacional Autónoma de México. Dirección General de Asuntos del Personal Académico (DGAPA), proyecto PAPIIT IN305719

\section{Referencias}

Asociación Americana de Psiquiatría. (2014). Manual diagnóstico y estadístico de los trastornos mentales DSM-5. Asociación Americana de Psiquiatría.

Bamba, B. M., Gómez, R. A. y Beltrán, M. O. (2017). El duelo y la pérdida en la familia. Revisión desde una perspectiva relacional. Redes, 36, 11-23. http://www.redesdigital.com.mx/index.php/redes/article/viewFile/196/159

Bellak, L. (1990). Test de apercepción temática, test de apercepción infantil y técnica de apercepción para edades avanzadas: uso clínico. Manual Moderno.

Bender, L. (1995). Test gestáltico visomotor, usos y aplicaciones clínicas. Paidós.

Bisquerra, R. (2009). Metodología de la Investigación Educativa. Editorial La Muralla.

Bowlby, J. (1993). El apego y la pérdida 3: La pérdida. Paidós.

Buck, J. N. (1995). H-T-P: manual y guía de interpretación de la técnica de dibujo proyectivo. Manual Moderno. Burns, C. R. y Kaufman, S, H. (1972). Action, Styles, And Symbols in Kinetic Family Drawings Kfd. Brunner/Mazel. Corman, L. (1967). Test del dibujo de la familia en la práctica médico-pedagógica. Kapelusz.

Cozby, C. P. (2005). Métodos de investigación del comportamiento (8a ed.). Mac Graw Hill.

Creswell, J. W. (2013). Qualitative inquiry and research design: Choosing among five approaches ( $3^{\mathrm{a}}$ ed.). Sage. Creswell, J. W. (2015). Educational research: planning, conducting, and evaluating quantitative and qualitative research ( $5^{\mathrm{a}}$ ed.). Pearson.

Dyregrov, A. (2008). Grief in Children. Second Edition. A handbook for adults. Jessica Kingskey.

Dolto, F. (1983). En el juego del deseo. Siglo XXI. 
Erskine, R. G. (2016). Presencia terapéutica y patrones relacionales. Conceptos y práctica de la psicoterapia integrativa. Karnac Books Ltd.

Esquivel, A. F. (2010). Psicoterapia infantil con juego. Casos clínicos. Manual Moderno.

Flanagan, D. P y Kaufman, A. S. (2012). Claves para la evaluación con WISC IV (2 a ed.). Manual Moderno.

Freeman, J., Epston, D. y Lobovits, D. (2001). Terapia narrativa para niños. Aproximación a los conflictos familiares a través del juego. Paidós.

Frank, J., DeMichele, A. y Wachtel, P. (1997). Persuasion and healing: a comparative study of psychotherapy. Psyccritiques, 42(5), 389-391. https://doi.org/10.1037/000359

Hammill, D. D., Pearson, A. N. y Voress, K. J. (1980). DTVP-2 Método de evaluación de la percepción visual de Frostig (2 $2^{\mathrm{a}}$ ed.). Manual Moderno.

Koppitz, E. (2007). El dibujo de la figura humana en los niños. Editorial Guadalupe.

Lebovici, S. y Weil- Halpern, F. W. (2006). La psicopatología del bebé. Siglo XXI.

Neymeyer, R. A. y Woring, C. (2008). Psychotherapy for complicated bereavement: A meaning-oriented approach, Illness, Crisis, Loss, 16(1), 1-20. https://doi.org/10.2190\%2FIL.16.1.a

Neimeyer, R. A. (2019). Meaning reconstruction in bereavement: Development of a research program. Death Studies, 43(2), 79-91. https://doi.org/10.1080/07481187.2018.1456620

Payás, P. P. (2010). Las tareas del duelo. Psicoterapia de duelo desde un modelo integrativo-relacional. Paidós.

Rosado, R. M. (2007). El enfoque integrativo en psicoterapia. IPyE: Psicología y Educación. 1(2), 42-50.

Stapert, M. y Verliefde, E. (2011). Focusing con niños, el arte de comunicarse con los niños y los adolescentes en el colegio y en casa. Desclée De Brouwer.

Tena, S. A. (2020). Psicoterapia integrativa: una aproximación a la práctica clínica basada en evidencias. Manual Moderno.

Tizón, J. (2004). Pérdida, pena, duelo: vivencias, investigación y asistencia. Paidós.

Tizón, J. (2007). Psicoanálisis, procesos de duelo y psicosis. Herder.

Tizón, J. L. (2019). Apuntes para una psicopatología basada en la relación: Vol. 3 Psicopatología general (Vol. $3)$. Herder.

Valero, M. S., Barreto, M. P. y Pérez, M. P. (2016). Familia y duelo: el apego y los acontecimientos vitales estresantes como predictores del desarrollo de duelo complicado. Familia: Revista de ciencias y orientación familiar, 53, 57-69. Recuperado de https://core.ac.uk/download/pdf/153481832.pdf

Wechsler, D. (2010). WISC IV Escala Wechsler de inteligencia para niños. Manual Moderno. 